\title{
CAMBIASSU

\section{RPG no ensino remoto: processo e produto, experiências com Literatura e prática esportiva}

\section{RPG in remote learning: process and product, experiences with Literature and sports practice}

\section{Richard Romancini}

Professor do Programa de Pós-Graduação em Comunicação da Universidade de São Paulo. richardromancini@usp.br

\section{Maria de Fatima Morina}

Graduada em Psicologia e Licenciatura em Letras pela PUCSP. Mestra em Gestão e Desenvolvimento da Educação Profissional (Centro Paula Souza, 2019). Curso atualmente a Licenciatura em Educomunicação da Escola de Comunicações e Artes da Universidade de São Paulo. fatimamorina@usp.br

\section{Flavio Chiari Oliveira}

Estudante da Licenciatura em Educomunicação da Escola de Comunicações e Artes da Universidade de São Paulo. flavio.chiari.oliveira@usp.br 


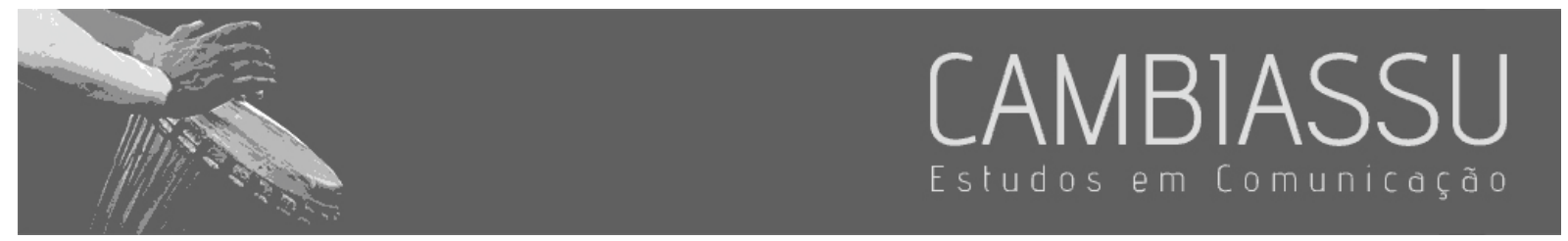

\section{Resumo}

O artigo descreve duas experiências de uso do Role-Playing Game (RPG), ou Jogo de Interpretação de Papéis, no ensino remoto emergencial (ERE). A discussão sobre o ERE e o tema dos jogos e educação é o contexto teórico do trabalho, que busca, a partir dos estudos de caso das práticas, apontar aspectos que podem contribuir para uma utilização produtiva do RPG no ensino remoto. Conclui-se, entre outros pontos, que é importante que o docente tenha bom conhecimento da forma do RPG, assim como das tecnologias que serão utilizadas no contexto didático, podendo optar por atividades mais voltadas à experiência de um jogo previamente elaborado ou ao desenvolvimento de um, com os alunos.

Paldvras-chave: RPG, Jogos, Educação, Tecnologias, Ensino Remoto.

\section{Abstract}

The article describes two experiences using the Role-Playing Game (RPG) in emergency remote teaching (ERT). The discussion about ERT and the theme of games and education is the theoretical context of the work, which seeks, from the case studies of practices, to point out aspects that can contribute to a productive use of RPG in remote learning. It is concluded, among other points, that it is important that the teacher has good knowledge of the RPG form, as well as the technologies that will be used in didactic context, and may choose activities more focused on the experience of a previously elaborated game or on the development of one, with the students.

Keywords: RPG, Games, Education, Technologies, Remote Teaching. 


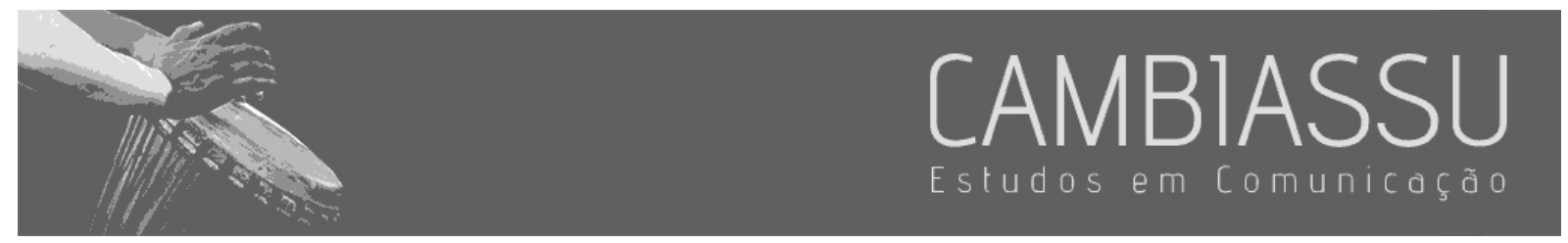

\section{Introdução}

Este artigo decorre de uma atividade desenvolvida em disciplina da Licenciatura em Educomunicação da Escola de Comunicações e Artes da Universidade de São Paulo, na qual os estudantes criam um jogo educativo, após estudos sobre aspectos pedagógicos e de design desses artefatos. Não há direcionamento formal ou temático, além do jogo ter preocupações educacionais, embora - por limitações de conhecimento técnico e de tempo - sugira-se a elaboração de jogos analógicos. Ao fim do curso, os estudantes, individualmente ou em grupos, realizam, além do jogo, um relatório sobre o desenvolvimento do trabalho.

Durante o curso, no primeiro semestre de 2021, dois estudantes orientados pelo docente (primeiro autor deste trabalho) fizeram trabalhos que foram além do protótipo, testando os jogos em contextos educativos reais. Isso foi favorecido por ambos atuarem como professores, podendo usar suas produções em diferentes contextos. A estudante coautora aplicou sua proposta, voltada ao ensino de Literatura, no Ensino Médio e o último coautor numa situação de prática esportiva universitária.

A proposta dos jogos e os relatos desses estudantes traziam novidades em relação aos jogos que têm sido feitos na disciplina1: o uso do gênero Role-Playing Game (RPG) e sua adaptação e jogabilidade para o ensino remoto, além do uso em contexto real.

Esses aspectos inovadores levaram ao interesse em reestruturar ambos os relatórios em um único artigo, inserindo-os em uma discussão mais geral sobre o RPG no ensino remoto. Acredita-se que a exposição dessas experiências, que desempenham o papel de dois pequenos estudos de caso na arquitetura metodológica deste artigo, evidencia aspectos relevantes sobre possibilidades de uso do RPG no âmbito mencionado.

Assim, temos a seguinte questão geral de pesquisa: quais pontos devem ser considerados na adaptação de RPGs para o ensino remoto? Ao realizarmos a análise das experiências, iremos apontar

\footnotetext{
1 Os jogos feitos podem ser vistos em: https://sites.google.com/view/jogosativistas/jogos-estudantis.
} 


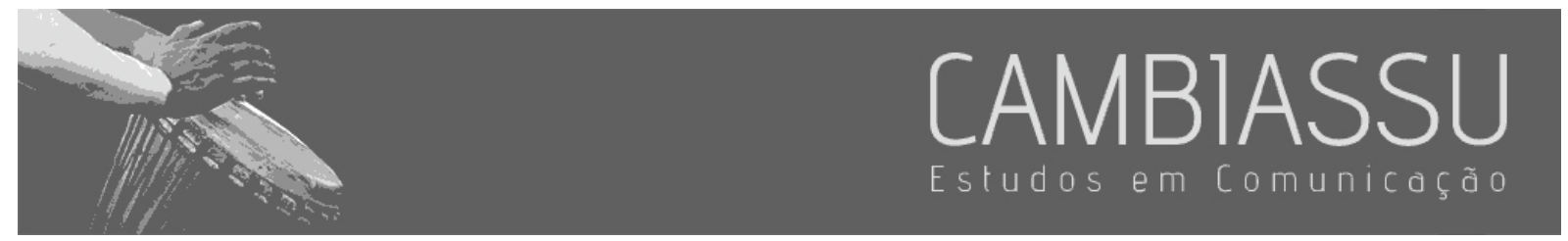

elementos que podem contribuir para elucidar essa questão. O objetivo do trabalho, portanto, é fazer uma análise das experiências mencionadas sobre o uso do RPG no ensino remoto.

A associação com o ensino remoto é o ponto principal de originalidade do trabalho, pois existem diversos estudos sobre o RPG na educação, inclusive no Brasil (COELHO; SILVA, 2020; PARISOTO; HAMMES, 2021). No entanto, há lacuna de conhecimento sobre a relação deste gênero de jogo com a referida modalidade educativa.

Após essa introdução, o artigo compreende tópicos sobre: 1) esclarecimentos sobre a noção de ensino remoto emergencial, 2) discussões sobre jogos e educação, bem como quanto ao RPG, 3) as descrições das práticas realizadas pelos coautores estudantes e 4) a discussão final do trabalho.

Deve-se notar, concluindo esse tópico, que os três autores são igualmente responsáveis pelo trabalho. No entanto, as redações das partes que descrevem as experiências didáticas foram elaboradas, basicamente, pelos estudantes.

\section{0 ensino remoto emergencial}

Hodges et al. (2020) defendem que o termo ensino remoto emergencial(ERE) é mais adequado do que ensino ou educação a distância para definir os casos em que circunstâncias excepcionais (como guerras e conflitos, crises sanitárias etc.) impedem a educação no formato presencial, levando a outras estratégias pedagógicas. A EAD, como notam os autores, está relacionada não somente à ausência da copresença física de docentes e discentes, mas ao planejamento rigoroso de atividades didáticas, realizadas com diferentes meios de apoio à instrução. Isso foi impossível na súbita migração da oferta educativa após a pandemia da Covid-19. A ampla aceitação do termo ERE como descritor da forma de educação que passou a ser realizada globalmente deve-se a isso.

Pelo que se disse, o ERE pode ser definido como uma "mudança temporária na forma de ensinar, utilizando uma modalidade alternativa de transmissão de conhecimento devido a 


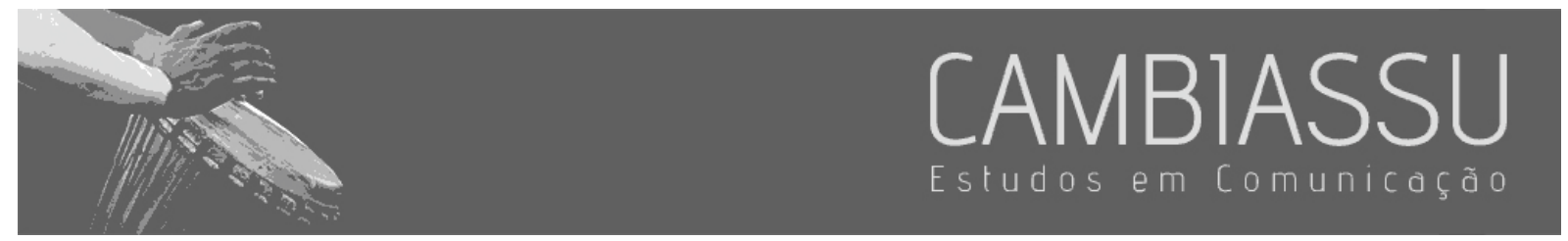

circunstâncias críticas" (Hodges et al., 2020, p. 96). Pelo teor abrupto e não previamente planejado das situações que provocam a necessidade do ERE, ele tende a exigir que os professores sejam os principais responsáveis pela transição entre as modalidades educativas, sem possuir apoio direto, como nos cursos tradicionais de EAD, de equipes das instituições em que atuam para administrar a situação educativa imposta.

Nesse sentido, o uso de tecnologias no ERE pode ser mais precário, menos criativo e sujeito a dificuldades relacionadas ao domínio e segurança dos docentes no ambiente das aulas. Mas o ERE pode representar, também, um momento de experimentação e novos aprendizados, para docentes e discentes.

Notando que outras situações emergenciais podem ocorrer no futuro, Hodges et al. (2020) defendem que a competência no ERE deve se tornar uma habilidade dos docentes. Essa habilidade pode ser reforçada pelo conhecimento de boas práticas - como as que procuramos analisar neste artigo - que tenham se realizado na modalidade em questão. Também é possível imaginar que certas atividades pedagógicas no formato do ensino híbrido - ou seja, aquele em que há momentos de presencialidade física conjunta e outros nos quais mediações tecnológicas substituem isso - possam se beneficiar ou ser inspiradas pelo tipo de conhecimento que este trabalho procura desenvolver.

\section{Jogos e educação}

A preocupação em renovar métodos e estratégias pedagógicas é um dos principais estímulos, nas últimas décadas, para as reflexões, pesquisas e práticas que buscam associar jogos e educação. Teóricos como Gee (2007), Prensky (2012) e Zagal (2010) exemplificam essa tendência. O caráter inovador das ações educativas desse tipo é associado à possibilidade dos jogos na educação promoverem aprendizagens mais ativas (WHITTON, 2014). 


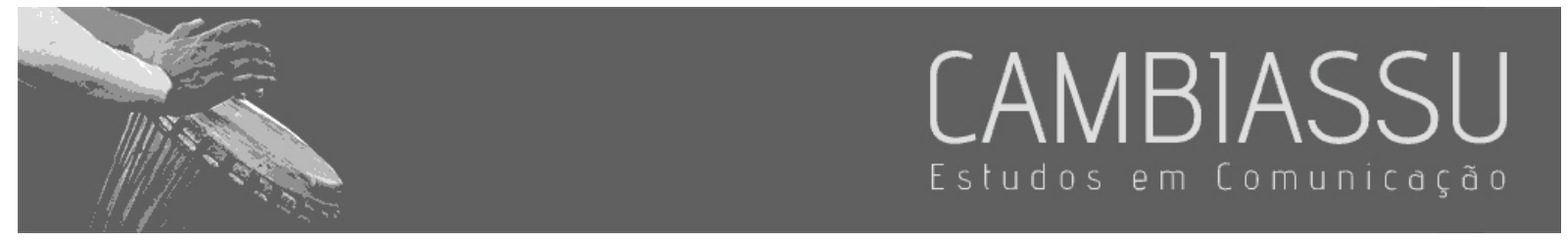

Há múltiplas formas de relacionar jogos e educação. Whitton (2014), referindo-se especificamente aos jogos digitais e ao aprendizado, aponta oito trilhas de estudo e prática: 1) o aprendizado com jogos de entretenimento; 2) o aprendizado com jogos educativos; 3) o aprendizado inspirado por jogos, isto é, como um contexto indireto de aprendizado, por exemplo, quando um professor usa o xadrez para estimular a feitura de algoritmos; 4) o aprendizado dentro dos jogos, considerando, então, as aprendizagens informais que ocorrem quando os jogos de entretenimento são utilizados; 5) o aprendizado sobre jogos, isto é, o estudo dos jogos entendidos como artefatos culturais; 6) o aprendizado a partir dos jogos, com a análise, pelos educadores, dos princípios construtivos que os jogos possuem que podem ser transferidos para situações educativas (caso da gamificação); 7) o aprendizado mediante a criação de jogos; e 8) o aprendizado dentro de comunidades de jogadores.

Esses caminhos não são excludentes e podem se cruzar ou se sobrepor nas trajetórias de educadores e educandos. Vale notar, ainda, que a chamada "aprendizagem baseada em jogos" (gamebased learning) pode ocorrer tanto com os jogos de entretenimento quanto com os educativos, também chamados de instrucionais ou de aprendizagem, ou seja, aqueles jogos "destinados a ajudar os jogadores a desenvolver novas habilidades e novos conhecimentos, ou a reforçar os já existentes" (BOLLER; KAPP, 2018, p. 40).

Outra camada de complexidade é que as discussões e ações didáticas com jogos podem se dirigir a áreas específicas da educação formal - em níveis de ensino (infantil, fundamental, médio e superior) e disciplinas - ou destacar âmbitos da educação não formal, por vezes com a preocupação de desenvolver habilidades e competências ligadas a atitudes e comportamentos.

Essas duas dimensões (conteúdos e comportamentos) são associadas por alguns autores, que observam que os jogos educativos possuem eficácia em termos de efeitos cognitivos-compreendendo os aspectos mencionados - e motivacionais. Os primeiros "incluem o ensino de conteúdo, oferecer a oportunidade para praticar habilidades, aperfeiçoar um modelo mental ou relacionar conhecimento e 


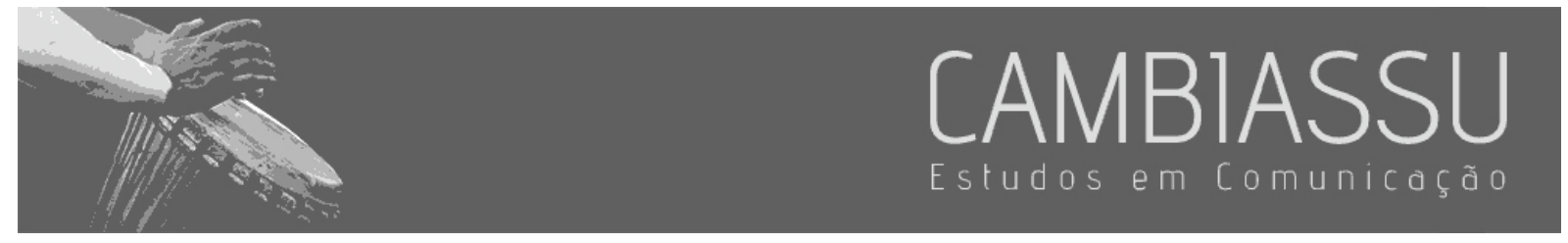

desempenho" (HAMMER et al., 2018, p. 285, tradução nossa). Já os efeitos motivacionais enfatizam "a intensidade, persistência e qualidade do envolvimento do jogador. Por exemplo, ao escolher voluntariamente ler sobre história depois de jogar Civilization" (HAMMER et al., 2018, p. 285-286, Tradução nossa).

Em revisão da literatura sobre jogos e aprendizado, Hammer et al. (2018) observam que, sob determinadas circunstâncias, a aprendizagem baseada em jogos pode ser positiva, com resultados, em termos cognitivos, até melhores que outras atividades. Mas, para isso, o design do jogo é relevante - compreendendo aspectos como a existência de um objetivo instrucional, a capacidade do jogo propiciar uma experiência interessante e envolvente para o jogador e o balanço adequado entre diversão e instrução (BOLLER; KAPP, 2018). No entanto, tão importante quanto o design do jogo é a experiência de aprendizado ao qual ele se associa. Oportunidades de discutir, aplicar ou transferir o conhecimento obtido no jogo para outros contextos também são aspectos que reforçam a qualidade educativa de uma experiência com jogos.

A meta de elaborar um produtor educativo envolve outras dimensões como a atividade pedagógica mais ampla no qual ele poderá se situar. Por isso, os alunos são estimulados a preverem, em seus relatórios, contextos de aplicação e sequências didáticas que envolvam o jogo.

\section{RPG e educação}

Em primeiro lugar, é válido definir o que é um RPG. Essa tarefa, como notam Zagal e Deterding (2018), é complexa, uma vez que, após o primeiro jogo do tipo, Dungeons \& Dragons (D\&D), de 1974, seguiu-se um desenvolvimento com múltiplas direções e estilos. De qualquer modo, os autores arrolam características definidoras dos jogos de RPG como: envolver a "criação estruturada de regras e encenação de personagens em um mundo ficcional", no qual os "jogadores geralmente criam, representam e governam individualmente as ações dos personagens, definindo e perseguindo seus 


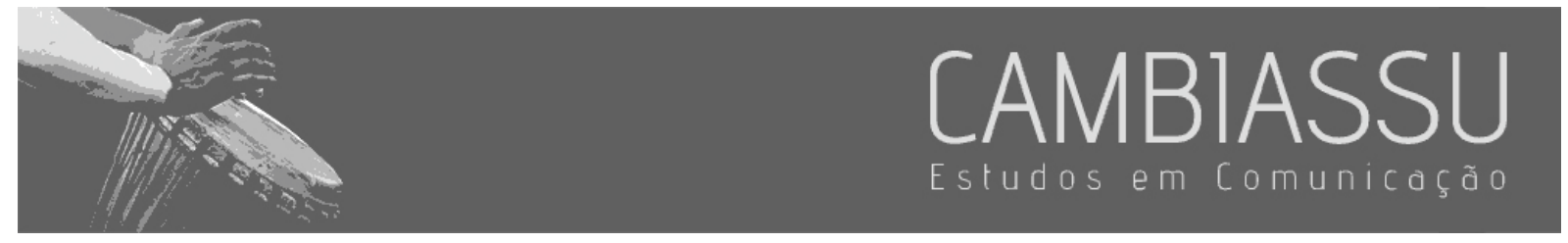

próprios objetivos, com grande margem de escolha sobre quais ações podem realizar" (ZAGAL; DETERDING, 2018, p. 46, Tradução nossa). Outras definições são parecidas, enfatizando os aspectos narrativos e imaginativos, como a de Schmit (2008, p. 47): "[o RPG é uma] contação de histórias interativa, quantificada, episódica e participatória". Vale também notar que os RPGs possuem regras para a progressão dos personagens, tarefas e resoluções de conflitos, e o mundo do jogo é administrado por árbitro humano ou computador.

Há, de acordo com Zagal e Deterding (2018), quatro formas principais de RPG: de mesa, liveaction (ou LARP), solo com computador e de múltiplos jogadores on-line. As duas primeiras são tipicamente menos estruturadas, além de não precisar, necessariamente, envolver dispositivos digitais; seus materiais de jogo são: livros de regras, fichas de personagens, dados, folhas de anotações e componentes. Os livros de regras funcionam como um sistema que organiza e contextualiza as ações do jogo e dos personagens. No caso da forma live-action, as ações são desempenhadas como no teatro, com os jogadores representando os personagens não apenas oralmente, como no RPG de mesa.

Nessas formas, com geralmente copresença física dos jogadores, um participante assume o papel de Mestre - também conhecido como narrador, dungeon master, game master, storyteller, guardião, keeper-e começa a partida, descrevendo a situação inicial. Depois, cada jogador define sua ação e o jogo/narrativa continua em rodadas. O Mestre também controla os non-player characters (NPCs) - personagens sem jogadores - e é o juiz das ações, descrevendo as consequências quando as regras não as explicitam, determinando a dificuldade de se obter sucesso em ações dos personagens dos jogadores (VASQUES, 2008).

O fato de que em qualquer forma de RPG a representação ou interpretação de papéis seja fundamental aproxima, inicialmente, esse tipo jogo da dimensão educativa, pois fingir se relaciona, em crianças, ao desenvolvimento cognitivo e social, e em adolescentes à experimentação de papéis sociais 


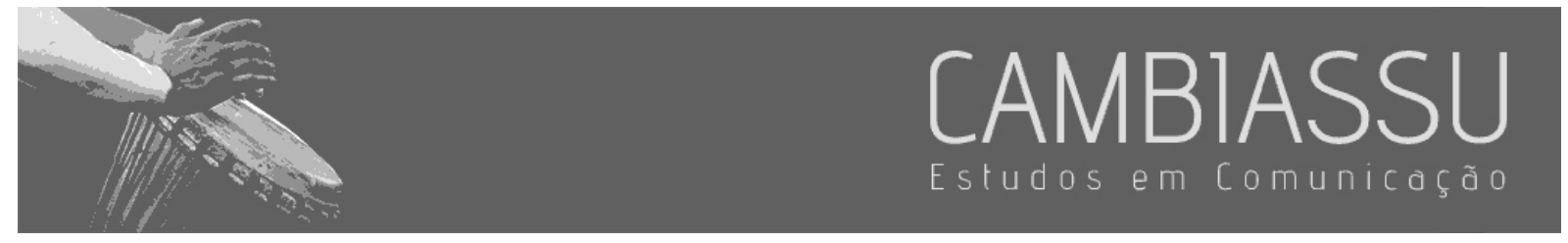

(HAMMER et al., 2018). A própria educação de adultos, médica ou militar, por exemplo, possui tradição na simulação de situações.

Para Grando e Tarouco (2008) o RPG possui características que o auxiliam a ser uma ferramenta educacional, como a socialização, a cooperação, a criatividade, a interatividade e a interdisciplinaridade. Também sobre as características educacionais dos RPGs, Hammer et al. (2018), sob a lente de diferentes teorias de aprendizagem, apontam cinco principais: 1) a adoção de um personagem, que permite que o jogador/estudante assuma a perspectiva de alguém diferente dele e simule experiências; 2) a manipulação de um mundo ficcional, o que faz com que o jogador tenha que prever consequências de suas ações, como no método científico; 3) a alteração do senso de realidade, que facilita a mudança de esquemas mentais e desenvolve o raciocínio ético; 4) a experiência da imaginação compartilhada, que favorece o desenvolvimento de habilidades sociais, pela colaboração e escuta entre jogadores; e 5) a possibilidade dos jogadores/estudantes produzirem RPGs, que se relaciona a abordagens, como a construcionista, que valorizam a aprendizagem pela ação. Os autores citados também destacam que há "circunstâncias ideais" para o RPG no apoio à aprendizagem. Retomaremos esse ponto, na conclusão.

\section{A experiência com a Literatura no Ensino Médio}

A metodologia para teste do uso do RPG de mesa na Literatura consistiu na realização de uma iniciativa com os primeiros anos do Ensino Médio integrado ao Técnico de Informática e ao Técnico de Logística, cujos alunos estudam em período integral - na escola em que a autora atua - o que torna o ensino remoto on-line, devido à pandemia da Covid-19, ainda mais desafiador.

O desenvolvimento do RPG teve como tema o período literário do Humanismo, especificamente a obra de Gil Vicente, no século XVI, em Portugal - o que é, normalmente, um desafio enfrentado pela 


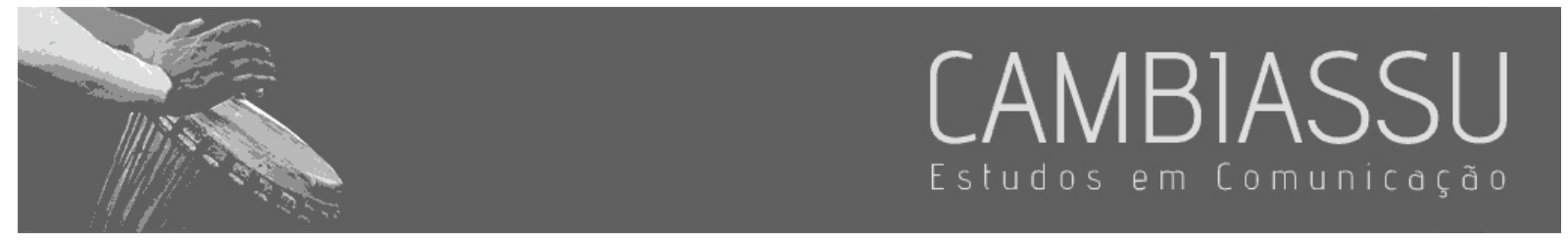

docente com a encenação teatral de seus autos. No entanto, dado o contexto referido, as aulas se davam pela plataforma Teams da Microsoft, impossibilitando a abordagem usual.

A obra escolhida foi o Auto da Barca do Inferno que, além de contar com o Anjo e o Diabo, coloca em evidência o "dia do juízo final" do Cristianismo, a acontecer com a morte dos personagenstipo, entre outros: o nobre tirânico que pagava pessoas para rezarem por ele; o juiz e o corregedor corruptos; o padre com namorada; o judeu com seu bode em plena perseguição antissemita em Portugal e o parvo que morreu de caganeira (o ingênuo e humilde).

Cada um desses personagens foi assumido voluntariamente por alunos, os demais assistiram ao RPG e atuaram como juízes ao fim de cada julgamento de vida pregressa conduzido pela Mestra (papel assumido professora) e, portanto, fizeram o papel de Anjos e Diabos.

Depois do julgamento desses, eram jogados os dados tradicionais do RPG, embora em sua versão virtual, pela Mestra, pois como as aulas eram virtuais, não havia como o próprio protagonista fazer isso.

Conhecer bem a obra a ser adaptada para o RPG ajudou muito e foi a partir de sua estrutura narrativa e dialogal que se obtiveram subsídios para definir as regras do jogo que seguiram uma dinâmica muito simples, tal como são os autos de Gil Vicente, com um ato e um cenário único - um rio, um cais e dois barcos - um que vai para o inferno e outro que vai para o paraíso.

A dinâmica central do RPG didático proposto foi a defesa das almas e o seu julgamento, uma a uma. A atividade foi divertida, porque havia a expectativa do julgamento da plateia-júri e o rolar do dado de vinte lados para confirmar o veredito ou não, o que fazia com que o rumo da narrativa mudasse repentinamente e as injustiças acontecessem - como na vida real. A experiência com o RPG ocupou três aulas e teve desdobramento na discussão da temática.

O objetivo geral de se usar o RPG de mesa para estudar Literatura foi despertar o interesse dos alunos nas obras do Humanismo numa situação como esta do contexto pandêmico, definindo o 


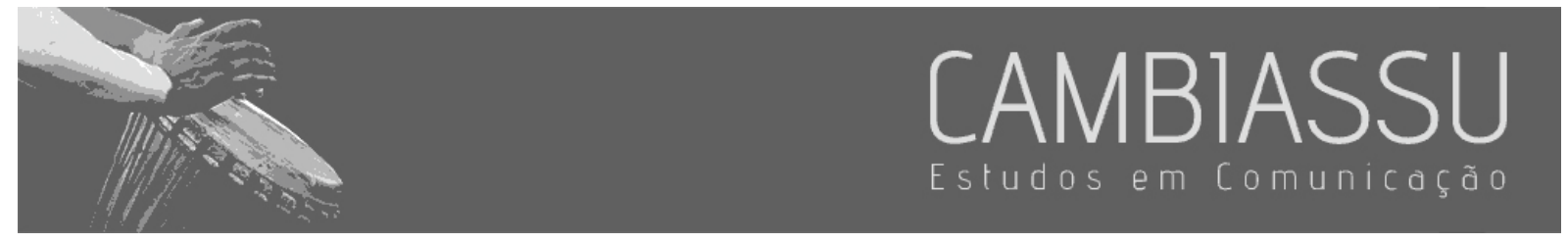

destino de personagens-tipo criados por Gil Vicente no Auto da Barca do Inferno, embora seu nome não fosse anunciado aos alunos previamente. Já as metas instrucionais, plenamente atingidas, foram permitir que os alunos vivenciassem a obra literária escolhida e experimentassem os valores da época em que foi escrita, bem como o estilo do autor.

O desenvolvimento do RPG se deu da seguinte forma: a Mestra, para dar início, colocou música e imagens de paraíso e inferno, descreveu todo o cenário e o contexto, apresentando um a um dos personagens à medida que cada um entrasse em ação. A dinâmica foi simples porque as almas a serem julgadas entravam no jogo uma de cada vez, quando a Mestra as apresentava:

- O personagem fazia sua defesa conforme as características e habilidades descritas na ficha criada uma semana antes pela Mestra (Figura 1), a qual ele, portanto, já havia estudado;

- A plateia-júri (Anjos e Diabos):

- julgava as ações do personagem que acabara de se defender;

- votava pela enquete do Teams;

- argumentava pelo microfone ou pelo chat do Teams;

- A Mestra rolava o dado virtual de vinte lados para confirmar o veredito da plateia-júri, sendo o veredito confirmado se o resultado fosse de um a dez ou negado quando de onze a vinte;

- Se a alma fosse para o inferno, a Mestra compartilhava um vídeo com o diabo dando risada assustadoramente;

- Se a alma fosse para o paraíso, a Mestra compartilhava um vídeo com anjos cantando em meio a nuvens e muita luz.

Figura 1. Exemplo de Ficha de personagem 

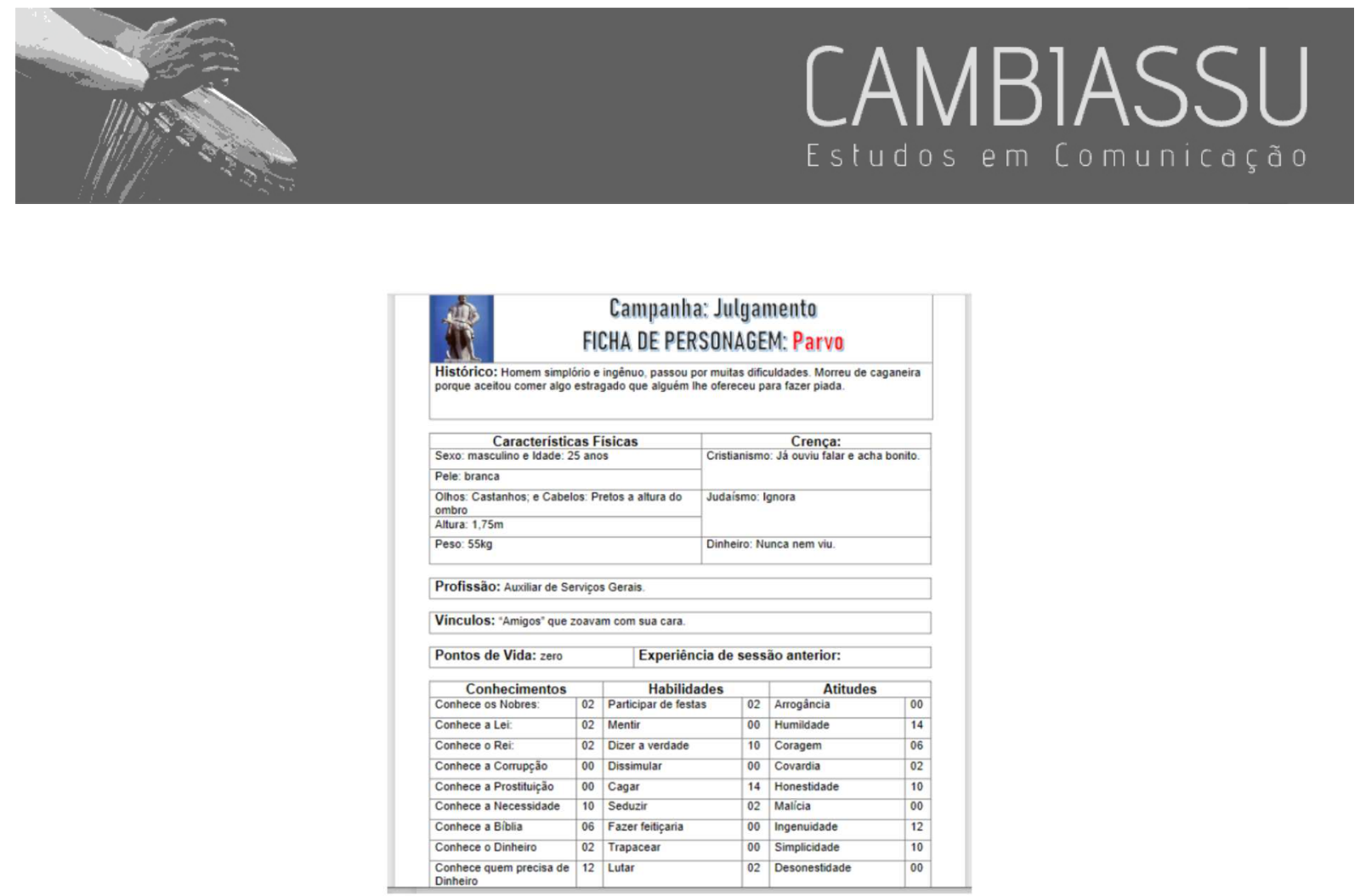

As regras essenciais consistem na história proposta pela Mestra, seus desafios e respostas a esses, bem como seguir as características dos personagens descritas nas respectivas fichas. Isso foi interessante porque os alunos se fantasiaram com vestimentas e maquiagem, alteraram suas vozes e sua linguagem para seguirem de fato as referências fornecidas.

Todos entraram no mundo do "Como se", que é um termo do psicodrama empregado no roleplaying ou jogo de papéis, mas que aqui contribui para o entendimento das ações tomadas no jogo.

A reação dos alunos foi muito positiva, pois pediram explicitamente para que outras obras literárias tivessem o mesmo tratamento, além disso o aprendizado ficou visível nas aulas seguintes, quando a obra, seus personagens, suas características e principalmente sua estrutura narrativa e seu contexto artístico e histórico foram retomados. Os alunos fizeram comentários textuais no ambiente, demonstrando envolvimento, diversão e elogio à aula, por exemplo: "Vou mandar todo mundo pro inferno kajsjakjsa”, "RACHEI COM O ‘EFEITO SONORO’ KQKAAKKAKQKAKAKA”, “Até mais, prof, adorei a iniciativa do jogo".

O volume dessas participações também oferece outro indicador do interesse, pois, ao se comparar as classes em que o tema foi abordado com o RPG e não (isso foi possível pela situação de aulas da autora), no primeiro caso, o volume de participações dos estudantes foi sempre bem maior: 


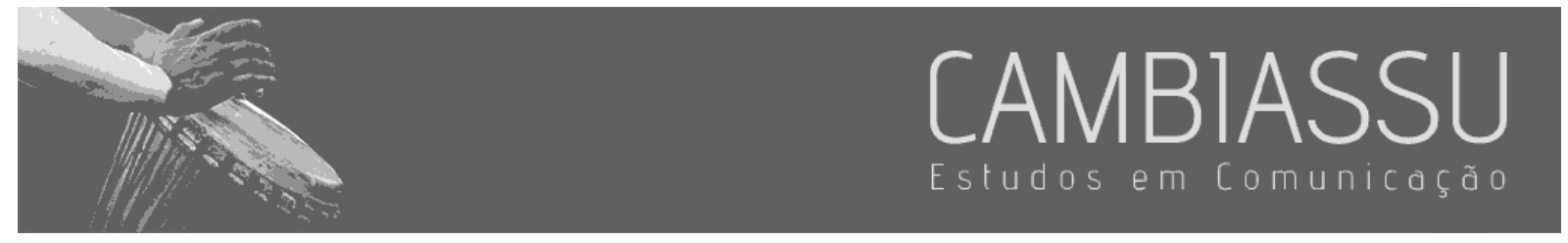

309 participações textuais no ambiente Teams numa classe com RPG e 44 na que não teve esse dinâmica e, em outra aula, respectivamente 210 e 28 comentários dos estudantes.

\section{A experiência com a prática esportiva}

O esporte no Ensino Superior é amador; os praticantes o fazem porque gostam, sem remuneração e assumindo gastos. Isso significa que, se já é um esforço considerável recrutar novos integrantes e manter os atuais, quando a prática em quadra e ao lado dos amigos se inviabiliza, há um desafio a mais.

Alternativas mais óbvias podem ser utilizadas, como a criação de rotinas de treino físico e/ou técnico para os atletas executarem em suas residências, a exploração de outros recursos, como "gincanas" em grupo, encontros remotos para análises de jogos, a assistência coletiva de filmes, lives com ex-alunos, convidados praticantes do esporte, entre outras. Com isso, vários treinadores aprenderam a gravar e editar vídeos, criar planilhas personalizadas, entender sobre engajamento em rede social.

A simulação via videogame é uma alternativa adicional, favorecida pela evolução dos jogos de console nos últimos anos, que os aproxima fortemente da realidade. E a jogabilidade, mais especificamente a forma como cada atributo de performance do personagem interage entre si e com os de outros players (controlados pela máquina ou não), também progrediu.

Entretanto, essa forma de substituição da prática tradicional não é tão acessível, por questões como o custo, disponibilidade do jogo e do dispositivo e, quando o jogo é praticado on-line, é necessário que a conexão à internet de todos tenha qualidade, o que nem sempre ocorre. É possível, além disso, trapacear nos jogos de console e a melhora dos atributos do personagem é rápida, o que não condiz com a realidade. Por fim, não há nesse tipo de jogo a prerrogativa "parar para explicar" o que está ocorrendo e por quê. 


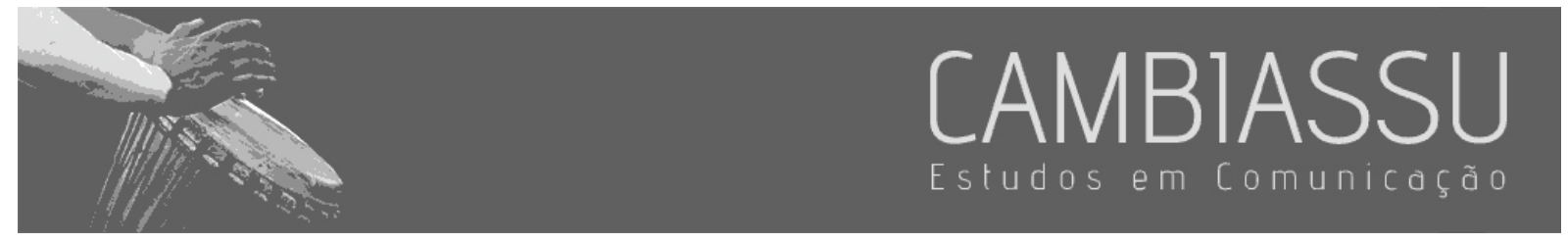

É nesse contexto que surgiu a ideia de desenvolvimento e aplicação de um jogo de RPG para o treinamento físico e esportivo relacionado ao basquete. O jogo, que utiliza a forma do RPG de mesa, foi chamado de Cesta de Tabuleiro, e simula a dinâmica do esporte, com os atributos dos jogadores colidindo e sendo alterados pelas condições da partida e com o passar do tempo.

A proposta objetivou, ainda, apoiar o desenvolvimento de conhecimentos táticos sobre basquete, permitindo a prática esportiva, por meio dessa adaptação. Pelo que se disse, é recomendado que os jogadores possuam um repertório de médio a avançado sobre o esporte. É fundamental, ainda, que a partida seja guiada por um especialista no assunto, como um treinador ou um jogador experiente. Ele atuará como o Mestre de uma sessão de RPG, por exemplo, prescrevendo o que é possível ou não, dando eventuais dicas e ajudando a definir se houve vencedor.

O jogo poderá ser utilizado como uma ferramenta de ensino em um plano de treinos, assim, o técnico decidirá, eventualmente em conjunto com sua equipe, o enfoque das disputas. Contudo, os primeiros momentos devem ser usados para instruir a todos como se envolver com o jogo.

O jogo é síncrono e tem - na modalidade de ensino remoto - que ser realizado em determinado ambiente digital. Após pesquisas, optou-se pela plataforma Spatial Chat (https://spatial.chat/), no qual o usuário entra numa sala e é simbolizado por um círculo na tela, contendo sua inicial, uma foto ou a imagem ao vivo de sua câmera. O site possui vários recursos, como alterar o plano de fundo, e para os treinos táticos e testes do jogo foi usado uma imagem de quadra de basquete; a possibilidade de colocar imagens que podiam ser controladas por qualquer um, o que serviu para inserir a bola da partida; e o mais importante, a liberdade de cada jogador se movimentar.

O Cesta de Tabuleiro foi desenvolvido/testado com uma Equipe de Basquete Masculino Universitário, em quatro sábados, no período noturno, quando a comissão técnica se reunia com o time no Spatial Chat. A familiarização com o site já havia sido feita. A primeira coisa a ser feita era calibrar o zoom para que as posições em quadra fossem as mesmas para todos. Depois disso, relembravam o 


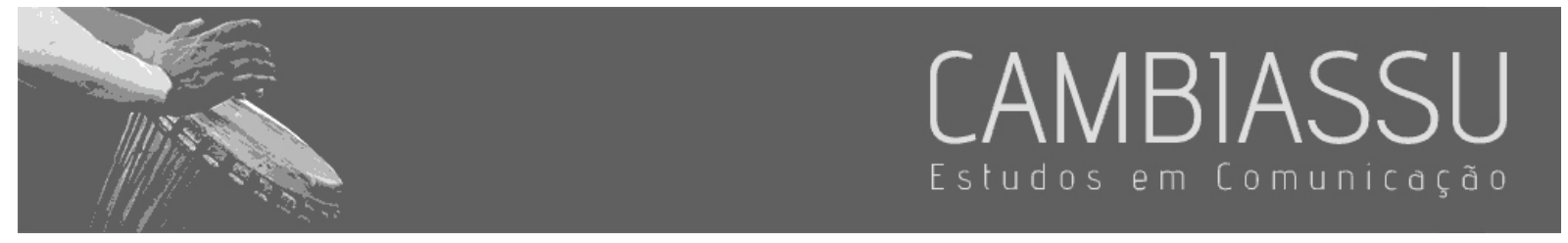

nome e os posicionamentos dos jogadores. Também era feito um recordatório com as particularidades de cada jogador e sua função (armador, ala, pivô e as possíveis combinações).

Após esse "aquecimento", cada dia teve como objetivo avançar na jogabilidade. No primeiro encontro, houve a combinação e a prática das ações básicas do jogo (troca de turnos, relatos das ações de jogo e suas sequências). Assim, acertou-se que se a bola fosse passada, o novo jogador com a posse é quem ditaria em sequência o que faria. No segundo encontro, conforme o jogo progredia, foram percebidos alguns entraves. Até onde vão as ações de quem tem a bola? E se a defesa quiser interceptar o passe? Como resolver a disputa de rebotes? Para resolver essas questões, realizamos debates, estabelecendo os limites de cada jogador e pesquisas para entender como funciona, de fato, uma partida. Levantamos as estatísticas do basquete: qual a frequência do passe interceptado, do rebote ofensivo, da cesta de três, da ponte aérea etc. Isso auxilia aos praticantes a entender que nem tudo é possível, mas que existe sempre uma alternativa para chegar à pontuação.

Entre o segundo e terceiro encontro foi proposto um aprofundamento analítico coletivo, de forma a todos estarem mais preparados para a próxima sessão. No terceiro encontro, foi adicionado o aspecto da aleatoriedade (com uso de dados de 20 faces, em gerador on-line), baseado em atributos de cada jogador. Foram utilizados poucos dados. Os armadores possuíam agilidade e finalização, os alas arremesso, e os pivôs finalização e força. Todos tinham passe e drible incluídos em seu arsenal. Para o momento defensivo, foi atribuído um único componente denominado defesa.

Logo percebemos que todos os jogadores possuíam todas as qualidades, só que por conta de sua posição e função, os aspectos mencionados eram diferenciados, direcionando-os para um estilo de jogo respectivo a cada um. Com isso, foi possível realizar uma partida satisfatória. As vitórias em cada tomada de decisão foram decididas através da conta (Atributo ofensivo - defesa = probabilidade de acerto em \%), quando o defensor decidisse confrontar a ação adversária, ou tomasse uma iniciativa de roubar a bola de alguma forma. Quando surgiam dúvidas, a intervenção do Técnico (Mestre do Jogo) 


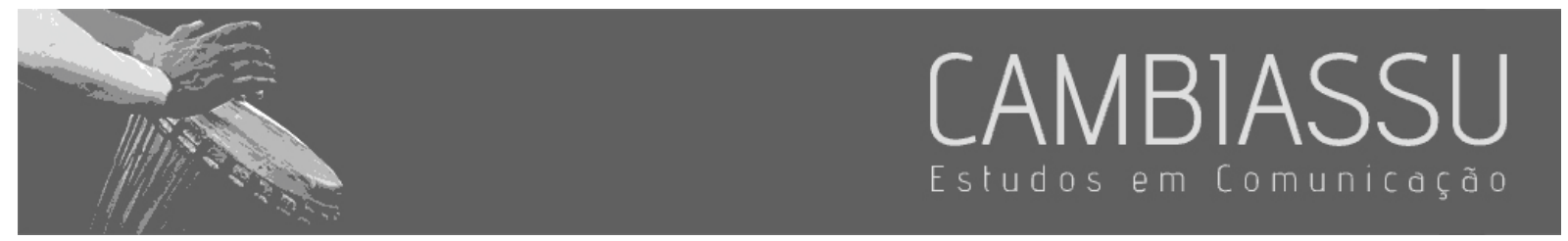

era necessária. Por fim, no quarto encontro, tentamos criar fichas mais robustas para cada um. Detalhamos mais alguns atributos (arremesso podia ser Longo ou Curto; defesa se dividiu em Toco, Roubada no Drible, Roubada no Passe), contudo quando feito os confrontos, a fórmula deixava algumas pontas soltas.

Visto que havíamos chegado num ponto realmente complexo, decidimos regular um fator determinante nos emuladores de console, no RPG e, consequentemente, na realidade: o tempo.

Nas partidas de RPG as ações dos jogadores são cumulativas e conectadas, ou seja, têm consequências. No jogo de videogame, o personagem controlado possui dois parâmetros de resistência física. Um para ditar o quanto é possível jogar no momento imediato, e outro é quanta energia o avatar tem no total, para ser gasto durante a partida. Ambos confluem em uma única "barra de stamina", que esvazia durante ações mais intensas, simbolizando o tempo decorrido jogando e a somatória de todas as ações até então.

Para fazer a contabilização da influência do tempo no jogo foi adotado o atributo de energia física. Praticamente os "pontos de vida" ou "stamina" do personagem. Esse atributo vai decaindo com o tempo, quer o jogador queira ou não, podendo ser recuperado caso ele fique sem executar certas ações. Entretanto, contamos as transições e cada mudança de posição na quadra, o que fez com que todos perdessem energia física de alguma forma.

Como apontado aqui, o jogo buscou ser realista. E, no caso do basquete universitário, que possui algumas equipes com no máximo oito jogadores (que treinam menos que profissionais), ocorre uma piora mais expressiva das técnicas ao final das partidas devido à fadiga. Então, para incentivar os atletas a se cuidarem, fez-se necessário agir até de forma mais fiel e rígida em relação às possibilidades que eles encontrarão em situações presenciais.

Analisando a experiência, notamos que a evolução obtida em apenas quatro encontros foi acima do esperado. Provavelmente pelo fato de a equipe de basquete testada ter muita disposição e 


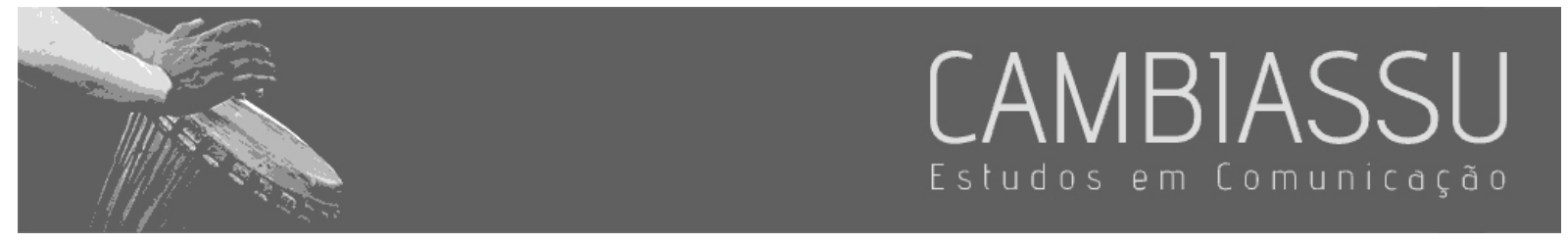

interesse no assunto, dando ideias e ajudando a encontrar soluções para os problemas que surgiam. Também foi propício o técnico ser o desenvolvedor do jogo, e ter uma boa noção da linha de ação que deveria ser tomada. Sem contar que as fontes de inspiração, como os jogos de console, já indicavam as variáveis necessárias. A questão era como amarrar tudo num formato coeso e educomunicativo, ou seja, que buscasse conjugar adequadamente o aspecto educativo e comunicativo da proposta.

Ao fim, ficou claro que se deve manter certa flexibilidade nas regras do jogo. O intuito dele não é criar algo para simplesmente passar o tempo, mas que sirva como uma possibilidade extra de oportunizar o aprendizado de algo. Uma nova ferramenta nas mãos do professor/treinador. Então as "regras do jogo" foram nomeadas de uma forma diferente: viraram "orientações para o jogo".

\section{Conclusão}

É possível, agora, concluir com indicações, retiradas das experiências descritas, de estratégias válidas para o desenvolvimento do RPG no ensino remoto, que se colocam como recomendações aos interessados.

Inicialmente, é válido apontar aspectos que parecem relevantes para os satisfatórios resultados alcançados, nos quais ambas as propostas convergem:

- Aquisição de conhecimentos (ocorrido, principalmente, durante a disciplina na qual teve início o processo) sobre o RPG pelos professores, permitindo a eles, entre outros aspectos, a escolha de uma de suas formas, mais condizente com as situações práticas de ensino. Nas duas situações, foi, basicamente, a forma de RPG mais simples, isto é, de mesa, que foi bem adaptado para a situação do ensino remoto;

- Adequação entre as possibilidades dos recursos técnicos de mediação didática (no primeiro caso, basicamente, o ambiente virtual Teams e, no segundo, o site Spatial Chat) e o desenvolvimento das atividades; 


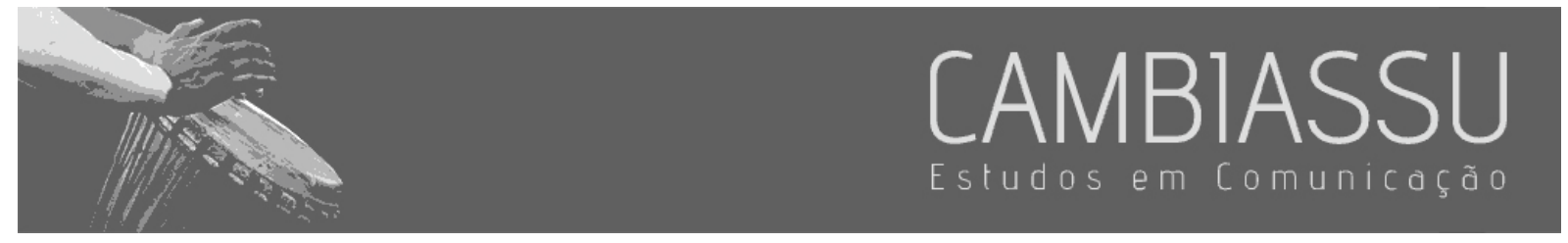

- Domínio pelos docentes e discentes das tecnologias utilizadas nas aulas;

- Conhecimento pleno do conteúdo abordado no jogo, pelos proponentes, permitindo-lhes elaborar iniciativas, com criatividade, nas quais o formato dos RPGs convergia com os objetivos e as metas pedagógicas estabelecidos previamente. Vale notar que, no caso do ensino de Literatura, a experiência anterior de utilização do teatro favoreceu o uso do RPG no ensino remoto;

- Inserção da atividade envolvendo o jogo num plano curricular mais amplo, de modo que aspectos abordados no jogo poderiam ser retomados (o que foi feito explicitamente no caso do ensino de Literatura) em outro momento de ensino, ajudando a consolidar aprendizados.

Nesse sentido, cabe retomar da discussão teórica a questão das "circunstâncias ideais" para o RPG no apoio à aprendizagem. Para Hammer et al. (2018, p. 296, Tradução nossa), isso está relacionado a uma "aprendizagem eficaz com RPGs [que] acontece quando as teorias de aprendizagem estão alinhadas com os pontos fortes da dramatização e são devidamente apoiadas pelo ambiente de aprendizagem". Os autores continuam o raciocínio, observando que os RPGs, por sua característica de experimentação prática com novas situações e adoção de papéis sociais, estão mais relacionados às teorias de aprendizagem construtivista e sociocultural.

Nessas duas abordagens há uma valorização do componente experiencial mais real das atividades educativas, na qual os estudantes podem aprender fazendo, inclusive elaborando um jogo. E é justamente isso que parece ter ocorrido, em muitos aspectos, na proposta de ensino voltada à prática esportiva, na qual se apelou à aquisição de conhecimentos pelos alunos para a construção do jogo (por exemplo, na busca de estatísticas de sucesso de certos eventos). A primeira proposta tinha, já de saída, um teor mais completo em termos do jogo.

A diferenciação observada, com uma atividade com maior ênfase no jogo, no produto e sua aplicação, e a outra no processo construtivo do artefato, não quer dizer que há diferença qualitativa 


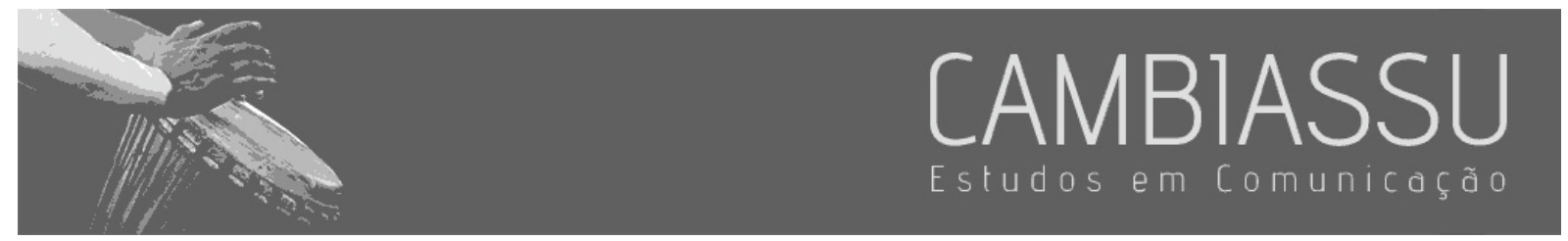

entre elas. O ponto principal, na escolha de uma dessas ênfases, está relacionado às intenções e possibilidades dos educadores, na sua interação com os educandos. De qualquer modo, a análise dos casos também indica essa dimensão relevante, quanto ao foco do jogo, no uso do RPG no ensino remoto e na educação de maneira geral.

\section{Referências}

BOLLER, S.; KAPP, K. Jogar para aprender. São Paulo: DVS Editora, 2018.

COELHO, I. M. A.; SILVA, F. A. R. Elaboração e aplicação de RPG didático como proposta para o ensino de biomas brasileiros. Revista eletrônica Ludus Scientiae - (RELuS), Goiânia, v. 4, n. 1, p. 49-62, 2020.

GEE, J. P. What video games have to teach us about learning and literacy. $2^{\mathrm{a}}$ ed. Nova lorque: St. Martin's Griffin, 2007.

GRANDO, A.; TAROUCO, L. O uso de jogos educacionais tipo RPG na educação. Revista RENOTE, Porto Alegre, v. 6, n. 1, 2008. DOI: https://doi.org/10.22456/1679-1916.14403

HAMMER, J.; TO, A.; SCHRIER, K.; BOWMAN, S. L.; KAUFMAN, G. Learning and Role-Playing Games. In: ZAGAL, J. P.; DETERDING, S. (Eds.). Role-Playing Game studies: transmedia foundations. Nova lorque: Routledge, 2018. p. 283-299.

HODGES, C.; MOORE, S.; TRUST, T.; BOND, A. A diferença entre ensino remoto emergencial e ensino a distância. Debate Terminológico, Porto Alegre, n. 18, p. 92-100, 2020.

PARISOTO, C. A.; HAMMES, I. L. "Entrando em cena": aprendendo sobre a conquista dos direitos trabalhistas a partir de um jogo de interpretação de papéis em estilo RPG. Educitec, Manaus, v. 7, e139921, 2021. DOI: https://doi.org/10.31417/educitec.v7.1399

PRENSKY, M. Aprendizagem baseada em jogos digitais. São Paulo: Editora Senac São Paulo, 2012.

SCHMIT, W. L. RPG e Educação: alguns apontamentos teóricos. 2008. 267 f. Dissertação (Mestrado em Educação) - Universidade Estadual de Londrina, Londrina, 2008.

VASQUES, R. C. As potencialidades do RPG (Role Playing game) na educação escolar. 2008. $169 \mathrm{f}$.

Dissertação (mestrado) - Universidade Estadual Paulista, Faculdade de Ciências e Letras de Araraquara, 2008.

WHITTON, N. Games and learning: research and theory. Nova lorque: Routledge, 2014.

ZAGAL, J. P. Ludoliteracy: defining, understanding, and supporting games education. Nova lorque: ETC Press, 2010.

ZAGAL, J. P.; DETERDING, S. Definitions of "Role-Playing Games”. In: ZAGAL, J. P.; DETERDING, S. (Eds.). Role-Playing Game studies: transmedia foundations. Nova lorque: Routledge, 2018. p. 19-51. 